\title{
Effect of Crocus sativus L. stigma (saffron) against subacute effect of diazinon: histopathological, hematological, biochemical and genotoxicity evaluations in rats
}

\author{
Alireza Timcheh Hariri', Seyed Adel Moallem², Mahmoud Mahmoudi ${ }^{3}$, \\ Bahram Memar ${ }^{4}$, Bibi Marjan Razavi ${ }^{5,6}$ and Hossein Hosseinzadeh ${ }^{2,6}$
}

\footnotetext{
Medical Toxicology Research Center, Faculty of Medicine, Mashhad University of Medical Sciences, Mashhad, Iran

2 Pharmaceutical Research Center, Pharmaceutical Technology Institute, Mashhad University of Medical Sciences, Mashhad, Iran. ${ }^{3}$ Immunology Research Center, Mashhad University of Medical Sciences, Mashhad, Iran

${ }^{4}$ Department of Pathology, Imam Reza Hospital, Mashhad University of Medical Sciences, Mashhad, Iran

${ }^{5}$ Targeted Drug Delivery Research Center, Pharmaceutical Technology Institute, Mashhad University of Medical Sciences, Mashhad, Iran

${ }^{6}$ Department of Pharmacodynamics and Toxicology,School of Pharmacy, Mashhad University of Medical Sciences, Mashhad, Iran
}

\section{Key Words}

Diazinon, Organophosphorus pesticides, Saffron, Crocus sativus, hematological and biochemical indices, genotoxicity, micronucleus assay.

\begin{abstract}
Objective: In this study, the effects of saffron stigma against subacute diazinon (DZN) toxicity on enzymes levels, biochemical, hematological, histopathological and genotoxicity indices were studied in rats.

Methods: Vitamin E (200 IU/kg) and the aqueous extract of saffron (50, 100 and $200 \mathrm{mg} / \mathrm{kg}$ ) were injected intraperitoneally three times per week alone or with DZN $(20 \mathrm{mg} / \mathrm{kg} /$ day, orally) for 4 weeks. The hematological and biochemical parameters were evaluated at the end of 4 weeks.
\end{abstract}

Results: Reticulocytes counts, alkaline phosphatase (ALP), aspartate aminotransferase (AST), alanine ami-

Received: May 10, 2017 Reviewed: Mar 16, 2018 Accepted: Mar 30, 2018 notransferase (ALT), lactate dehydrogenase (LDH), creatine phosphokinase, CPK-MB, gama glutamyl transferase (GGT), uric acid and micronucleus indices were increased significantly but total protein and RBC cholinesterase activity were decreased in the DZN-treated group. Saffron prevented the effect of DZN on GGT ( $50 \mathrm{mg} / \mathrm{kg}$ ), LDH, CPK and CPK-MB (100 and $200 \mathrm{mg} / \mathrm{kg}$ ) levels. An increased uric acid and reduced protein levels by DZN were prevented by vitamin $\mathrm{E}$ and some doses of saffron. A significant reduction was observed in platelets, RBC, hemoglobin and hematocrit indices in the DZN group. Saffron and vitamin $\mathrm{E}$ prevented this reduction. Vitamin $\mathrm{E}$ and saffron did not reduce the effect of DZN on RBC cholinesterase activity. The extract and vitamin E could not prevent DZN genotoxicity in the micronucleus assay. Other biochemical parameters and pathological evaluation did not show any abnormality in tissues of all groups.

Conclusion: This study shows that vitamin $\mathrm{E}$ and saffron reduce DZN induced hematological and biochemical toxicity. However, they do not prevent the genotoxicity induced by DZN. (c) This is an Open-Access article distributed under the terms of the Creative Common Attribution Non-Commercial License (http://creativecommons.org/licenses/by-nc/4.0/) which permits unrestricted noncommercial use, distribution, and reproduction in any medium, provided the original work is properly cited.

( $)$ This paper meets the requirements of KS X ISO 9706, ISO 9706-1994 and ANSI/NISO Z39.48-1992 (Permanence of Paper).
*Corresponding Author

Hossein Hosseinzadeh, Pharmaceutical Research Center, Pharmaceutical Technology Institute, Mashhad University of Medical Sciences, Mashhad, Iran. Tel.: +985138819042, Fax: +985138823251, E-mail address: hosseinzadehh@mums.ac.ir 


\section{Introduction}

Diazinon, an organophosphorus (OP) insecticide, has been used worldwide in agriculture and domestically for several years. The acute toxicity of OP is due to the irreversible inhibition of acetyl cholinesterase, the critical enzyme in neurotransmission [1]. Exposure to OP can cause several side effects such as arrhythmias, bronchoconstriction, bronchosecretion, miosis, involuntary defecation, nausea, vomiting, diarrhea, salivation, lacrimation, bradycardia, and urination. They also induce twitching of fine skeletal muscles, hyperreflexia, fasciculations, muscle weakness, paralysis that can affect diaphragm and respiratory muscles [2]. This causes accumulation of acetylcholine at cholinergic synapses leading to increased activation of nicotinic and muscarinic receptors. Recent studies indicate that pesticides intoxication produce oxidative stress by generation of free radicals and induce tissue lipid peroxidation in mammals and other organisms [3, 4]. Thus, oxidative stress is another mechanism that has been proposed for the toxicity of OP in animals and human. Diazinon reduces the activities of antioxidant compounds and induces oxidative stress [5].

Saffron, the stigma of Crocus sativus L. (Iridaceae), is a very delicate spice, flavor and a golden color. It contains many constituents such as picrocrocin and volatile compounds including safranal [6] as well as crocins (glycosyl esters of crocetin) that are unusual water soluble carotenoids and are responsible for its characteristic color $[7,8]$.

Different traditional uses of saffron such as anticancer, antiasthma, antihysteric, anticonvulsant, antispasmodic have been mentioned in some traditional books [9]. Saffron is a highly valued medicinal plant and some pharmacological activities such as anticancer [10], antidepressant [11], anti-tremor [12] and anticonvulsant effects [13-16] have been described for this herb.

Saffron and its constituents have shown protective properties against toxicities induced by either natural or chemical toxins such as acrylamide or diazinon [17]. Also, it showed antioxidant activity and reduced oxidative damages in different organs such as skeletal muscles [18], kidney [19], heart [20] and hippocampus [21]. It has been suggested that the antioxidant activity of saffron compounds can protect DNA and RNA from harmful chemicals [22]. Therefore, the aim of this study was to investigate the subacute effects of diazinon on biochemical and hematological indices, enzymes levels, histopathology and genotoxicity as well as the protective effects of saffron extract on these toxicities in rats.

\section{Materials and Methods}

\subsection{Animals}

Male Wistar rats (weighing approximately 220-270 g) were obtained from the animal house of Pharmaceutical Research Institute of Mashhad University of Medical Sciences. The animals were fed a standard laboratory diet and water ad libitum. Rats were kept at light-dark cycle (12h-12h) at a room temperature of $18-22^{\circ} \mathrm{C}$ at least two days prior to testing. All animal experiments were ap- proved by the Animal Care Committee of Mashhad University of Medical Sciences.

\subsection{Chemicals}

DZN (Merck Co, 99\% purity) was a gift from the Agricultural Research, Education and Development Organization (AREDO) (Tehran, Iran), vitamin E (DL-a Tocopherol acetate) from OSVE Pharmaceutical Co (Tehran, Iran), acridine orange from Merck and reticulocyte stain from Sigma- Aldrich.

Urea, creatinin (Creat), uric acid (UA), total and direct bilirubin (T\&D bil), total protein (Pr), albumin (Alb), alkaline phosphatase (ALP), aspartate aminotransferase (AST), alanine aminotransferase (ALT), total cholesterol (Chol), triglyceride (Tg), lactate dehydrogenase (LDH), creatine phosphokinase(CPK), CPK-MB, gama glutamyl transferase (GGT) and amylase commercial colorimetric kits were obtained from Pars Azmun (Tehran, Iran). Lipase kit was purchased from Randox (UK)

\subsection{Animal treatment schedule}

Rats were divided into 16 groups $(\mathrm{n}=6)$. The compounds were administrated in the morning (between 9:00 and 11:00 AM) to rats. All rats were treated for 4 weeks.

\section{Group 1: control group}

The control group received sweet almond oil at doses of 20 $\mathrm{mg} / \mathrm{kg}$ per day through gavages once a day.

Group 2: DZN treated group

DZN at a dose of $20 \mathrm{mg} / \mathrm{kg} /$ day in sweet almond oil was given through gavage to rats once a day

Group 3: vitamin E treated group

Vitamin E (200 IU/kg) was administered intraperitoneally three times per week

\section{Group 4: vitamin E + DZN treated group.}

Vitamin E (200 IU/kg three times per week) was administered intraperitoneally and DZN was administered orally $(20 \mathrm{mg} / \mathrm{kg}$ per day once a day in sweet almond oil) via gavage needle.

Group 5, 6, and 7: saffron + DZN treated group

Saffron was administered at doses 50,100 and $200 \mathrm{mg} / \mathrm{kg} /$ day intraperitoneally to rats three days per week before oral administration of DZN ( $20 \mathrm{mg} / \mathrm{kg}$ per day).

Group 8, 9, and 10: saffron treated groups

Saffron was administered at doses 50, 100 and $200 \mathrm{mg} / \mathrm{kg} /$ day intraperitoneally to rats three days per week.

\subsection{Measurement of body weight}

Body weight of control and treated rats were measured at the end of first and 4th weeks by automatic balance.

\subsection{Blood sampling and hematological assay}

After 28 days, animals were anaesthetized by chloroform. Blood samples were collected by cardiac puncture into tubes with anticoagulant (EDTA-K) and immediately analyzed for hematological parameters [red blood cell (RBC) 
count, hemoglobin (Hgb), hematocrite (HCT), white blood cell (WBC) count, mean corpuscular hemoglobin $(\mathrm{MCH})$, mean corpuscular volume (MCV), mean corpuscular hemoglobin concentration (MCHC), and platelets (PLT) by SYSMEX KX21 hematology analyzer. Blood samples in non-anticoagulant tubes were centrifuged at 5000 rpm for 15 min and serum was discarded.

\subsection{Biochemical evaluations}

Urea, creatinine, uric acid (U.A), total and direct bilirubin , alkaline phosphatase (ALP), aspartate aminotransferase (AST), alanine aminotransferase )ALT(, lactate dehydrogenase )LDH(, creatine phosphokinase )CPK), myocardial band enzymes of CPK (CPK-MB), Gamma Glutamyl Transferase (GGT), total cholesterol, triglyceride, total protein, albumin, and amylase were measured using commercial colorimetric kits.

\subsection{Reticulocyte count}

A microscopic procedure was used for counting reticulocytes. Brilliant Cresyl Blue was predominantly used until New Methylene Blue ("NMB") was introduced in 1949 by Brecher. The most recent National Committee for Clinical Laboratory Standards ("NCCLS") publication (NCCLS documentH44-P) calls for the use of a NMB stain in its reference method. An equal volume of blood was mixed with the NMB stain and incubated for at least three minutes, and up to fifteen minutes to allow the RNA to precipitate. A blood smear was made, and the stained reticulocytes were counted microscopically.

\subsection{Evaluation of micronucleus assay}

Acridine orange fluorescent staining method was applied to the micronucleus test in rats. The smears on clean slides were fixed with methanol for $5 \mathrm{~min}$ and stained with acridine orange according to the method of Hayashi and et al [23]. Acridine orange stock solution was prepared as a $0.1 \%$ aqueous solution that is stable for several weeks at 40C. Acridine orange $(0.24 \mathrm{mM})$ in $1 / 15 \mathrm{M}$ Sorensen's phosphate buffer ( $\mathrm{pH}$ 6.8), (2 parts of stock solution and 30 parts of buffer), was used as a working solution to stain slides for $3 \mathrm{~min}$ at room temperature. The slides were rinsed in the buffer 3 times for 1-3 min each time and then were mounted. Observations were made within a day. A Nikon fluorescent microscope with BG-12 excitation filter and 0-530 barrier filter was used for observation and microphotography.

\subsection{Evaluation of RBC cholinesterase activitys}

The activity of acetyl cholinesterase (AChE) in compact RBCs of rats was measured using Ellman method [24]. Briefly, after collecting $0.5 \mathrm{ml}$ peripheral blood, RBCs were separated by centrifugation and washed three times with normal saline. Then, $100 \mu \mathrm{L}$ of compact RBCs was lysed in distilled water and then was incubated with Di-Thiobis-Nitro-Benzoic acid + propyl thiocholine iodine (DT$\mathrm{NB}+\mathrm{PTCI}$ ), (containing quinidine sulfate as plasma cho- linesterase inhibitor and thiocholine Iodide as substrate) at $370 \mathrm{C}$ for $10 \mathrm{~min}$. Finally, the reaction was terminated by adding Hyamine (benzethonium chloride) $0.002 \%$, and the solution absorption was measured at $440 \mathrm{~nm}$ by spectrophotometer (Shimadzu, Japan). The AChE activity of the blood samples was calculated by multiplying the samples optical density (OD) to the converting factor $17.68 \mathrm{U} /$ $\mathrm{ml} /$ pack cell.

\subsection{Pathological evaluation}

At day 28, all of the rats were sacrificed for pathological evaluation. Kidneys, livers, lungs, pancreas and hearts were removed and macroscopically examined and fixed in $10 \%$ formalin. $5 \mu \mathrm{m}$ sections were prepared and stained with Hematoxylen \& Eosin for light microscopic findings.

\subsection{Statistical analysis}

The mean \pm SEM were determined for each study group. Data were analyzed by one-way ANOVA and Tukey multiple comparison procedure to calculate the significance. $\mathrm{P}<0.05$ value between study groups was taken as statistically significant. Data analyzing for a single group, beforeand after treatment, was done using Student's t- test.

\section{Results}

No death was observed in any of the experimental groups. Body weight was significantly decreased in the DZN-treated group after 4 weeks (table 1). Saffron only at the low dose increased body weights (table 1). Body weight was significantly decreased in DZN plus saffron treated groups (three doses) (table 1).

Macroscopic exams did not show any abnormality in physical characteristics of livers, kidneys, pancreas, lungs and hearts of all groups. In addition, a thorough light microscopic evaluation of these organs did not show any significant differences between different groups of rats either.

\subsection{Changes in enzymes levels}

AST (SGOT), ALT (SGPT), ALP, LDH, CPK, CPK-MB and GGT levels were increased significantly in the DZN-treated group when compared to the control group. Saffron significantly prevented this effect of DZN on LDH, CPK, CPK-MB levels by the doses 100 and $200 \mathrm{mg} / \mathrm{kg}$ and GGT levels by the dose $50 \mathrm{mg} / \mathrm{kg}$ (table 2). Vitamin E also inhibited the effect of DZN on LDH, CPK and CPK-MB.

All doses of saffron decreased this effect of DZN on ALP levels, however not significantly.

No statically significant changes in the levels of serum lipase, amylase, AST and ALT were observed among all groups (tables 2).

\subsection{Changes in biochemical indices}

DZN, vitamin E and saffron did not change serum urea, creatinine, cholesterol, triglyceride, total, direct bilirubin and 
albumin levels significantly (table 3 ). Total protein concentrations were decreased significantly in the DZN-treated group compared to the control group (table 3) A significant increase was observed in uric acid level in DZN and saffron (100 and $200 \mathrm{mg} / \mathrm{kg}$ ) groups (tables 3). An increased uric acid and protein levels by DZN were prevented by vitamin E and some doses of saffron (table 3 ).

\subsection{Change in hematological indices}

\subsubsection{RBC, hemoglobin and hematocrit indices}

A significant decrease was observed in RBC, hemoglobin and hematocrit indices in the DZN (table 4). These indices were significantly increased in the DZN plus saffron treated groups compared to the DZN treated group (table 4). Vitamin E also prevented the reduction in RBC, hemoglobin and hematocrit indices in the DZN plus vitamin E (table 4).

\subsection{2. $\mathrm{MCH}$ indices}

No statically significant change in $\mathrm{MCH}$ indices was observed among all groups.

\subsubsection{Platelets}

A significant decrease was observed in platelets counts indices in DZN treated group compared to the control group (tables 4). Platelets counts increased significantly when vitamin $\mathrm{E}$ or the high dose of the extract was used plus DZN (tables 4).

\subsubsection{WBC count}

No statically significant changes in WBC indices were observed among all groups, except with the high dose of saffron which increased WBC (tables 4).

\subsubsection{Reticulocyte count}

A significant increase was observed in reticulocyte counts in the DZN-treated group (table4). Reticulocytes counts were decreased significantly in the DZN plus vitamin E and saffron (at high dose) treated groups (table 4).

\subsection{Evaluation of erythrocyte (RBC) cholinest- erase activity}

A significant decrease was observed in RBC cholinesterase activity in the DZN-treated group compared to the control group $(\mathrm{p}<0.05)$. Vitamin $\mathrm{E}$ and two doses of saffron $(100$ and $200 \mathrm{mg} / \mathrm{kg}$ ) reduced the effect of DZN on RBC cholinesterase activity (tables 4 ).

\subsection{Evaluation of micronucleus assay}

The smeared preparation was stained with acridine or- ange. Findings showed a significant increase in micronucleus indices when the DZN-treated group compared with the control group. The extract and vitamin E could not prevent DZN toxicity in micronucleus assay (Figure 1).

\section{Discussion}

In this study, DZN changed some biochemical, enzymatic parameters, and hematological indices and induced genotoxicity. Vitamin E and saffron reduced DZN induced-hematological and some biochemical toxicity, but did not prevent the DZN-induced genotoxicity.

According to our results, DZN reduced RBC AChE activity and significantly decreased the weights of rats at the end of treatment. Due to anticholinesterase activity, DZN caused diarrhea and loss of fluids and electrolytes which led to weight loss [25]. DZN also increased some serum enzymes such as AST, ALT, ALP and LDH levels. Increase in these enzyme activities reflects liver damage which is dependent on exposure time and dose. For example, similar to our findings low dose DZN administration (10 mg/ $\mathrm{kg}$ ) for 30 days caused hepatotoxicity in rat as evidenced by an increase in ALT AST, ALP and LDH enzyme activities [26]. In another study, single orally dose of DZN (335 mg/ $\mathrm{kg}$ ) increased AST and ALT levels in rat serum [27].

Our results showed that the level of CK-MB was increased by DZN. CK-MB is one of the most sensitive and specific markers available for the evaluation of damage to the heart muscle. Increase in this marker has been shown in our previous studies [28, 29]. Increasing evidence revealed that long term exposure to OPs such as DZN inhibits cholinesterase activity and induces oxidative stress in different tissues including liver and heart [30, 31]. Increased the levels of oxidative stress markers such as malondialdehyde (MDA) and 8-iso-prostaglandin F2a has been reported following subchronic DZN exposure in these tissues [28, 29, 32].

In the present study saffron and vitamin E plus DZN showed no significant AChE inhibition, thus, they did not prevent the weight loss induced by DZN. Our results also indicated that saffron and vitamin E prevented the DZN-induced liver and heart damages. Saffron extract and its bioactive constituents have shown potent radical scavenging activity [33]. The protective effects of saffron as well as its active components such as crocin in different organ systems have been shown through antioxidant effects $[34,35]$. For example, crocin reduced DZN-induced hepatotoxicity via alleviating lipid peroxidation and reduction of elevated liver enzyme activities such as ALT and AST in rats [32]. Moreover, crocin modulated the endogenous antioxidants, reduced lipid peroxide formation and restored activity of CK-MB [35, 36].

In this study, vitamin $\mathrm{E}$ was used as a positive control. Vitamin E (a-tocopherol ) is considered as one of the most biologically active antioxidants in the biological system. It has been reported that vitamin E ameliorated the elevation of CK-MB and CPK levels due to DZN and doxorubicin-induced myocardial damage [29, 37]. Furthermore, in another study vitamin E protected liver against biochemical and histological toxicities induced by low level DZN exposure [26]. Our results also indicated that the 
effects of saffron aqueous extract on liver and cardiac injury markers are partially similar to vitamin E. So, saffron is able to reduce lipid peroxidation in pathological conditions such as DZN toxicity. According to the data, DZN induced anemia as evidenced by significant decrease in $\mathrm{RBC}$, hemoglobin and hematocrit. Similar to our results, the toxic effects of DZN on haematological indices have been shown in previous studies through oxidative stress $[38,39]$. It has been reported that OPs produce free radicals and interact with hemoglobin biosynthesis [40]. $\mathrm{MCH}$ is considered as a marker of hemoglobin in erythrocytes. In this study, the same rate decrease in RBC and hemoglobin counts were observed in DZN-treated rats. Therefore, $\mathrm{MCH}$ indices were not significantly changed.

Another blood index which was measured in this study was reticulocyte count. DZN increased the reticulocyte count. This index elevated when there is a lot of blood loss or red blood cells are destroyed prematurely [41].

The protective effects of vitamin E against DZN induced hematological toxicity has been demonstrated [38]. In our study, similar to vitamin E, saffron aqueous extract (100 and $200 \mathrm{mg} / \mathrm{kg}$ ) decreased hemoglobin and hematocrit increased by DZN. However, reduction in RBC and reticulocyte counts was observed only at $200 \mathrm{mg} / \mathrm{kg}$ of saffron aqueous extract. Therefore, aqueous extract of saffron can protect red blood cells from harmful oxidative damages induced by DZN [22]. In this study saffron ameliorated the DZN induced oxidative stress in erythrocytes, without any effect on erythrocyte AChE activity. These results are in agreement with our previous study which showed that crocin and safranal (constituents of saffron) protected RBCs against DZN toxic effects [42].

It has been reported that there is an association between oxidative stress and genotoxicity induced by chronic OP exposure [43]. To evaluate the genotoxic effects of sub-chronic DZN exposure, micronucleus assay was used. Results indicated that genotoxicity induced by DZN was not protected by vitamin $\mathrm{E}$ or saffron aqueous extract. Our results are not in agreement with other studies which showed that saffron and its constituents crocin and safranal were able to protect against methyl methanesulfonate (MMS)-induced DNA damage, as measured by the comet assay, in different mice organs $[44,45]$. Moreover, in another study oral pretreatment with saffron (20, 40 and 80 $\mathrm{mg} / \mathrm{kg}$ ) could inhibit the genotoxicity induced by cisplatin, cyclophosphamide, mitomycin $\mathrm{C}$ and urethane in the mouse bone marrow micronucleus test [46]. This discrepancy may be due to saffron different doses and different exposure times. The effect of saffron aqueous extract on micronucleus index are similar to the effect of saffron constituents in our previous study [42].

\section{Conclusion}

Our study shows that subacute DZN exposure changes some biochemical, enzymatic parameters, hematological indices as well as induces genotoxicity in rats. Vitamin $\mathrm{E}$ and high doses of the aqueous extract saffron partially reduce DZN toxicity; however, these agents do not decrease the genotoxicity effect of DZN.

\section{Acknowledgements}

The authors are thankful to the Vice Chancellor of Research, Mashhad University of Medical Sciences for financial support. The results described in this paper are part of a Ph.D. thesis.

\section{Conflict of interest}

The authors declare that they have no competing interests.
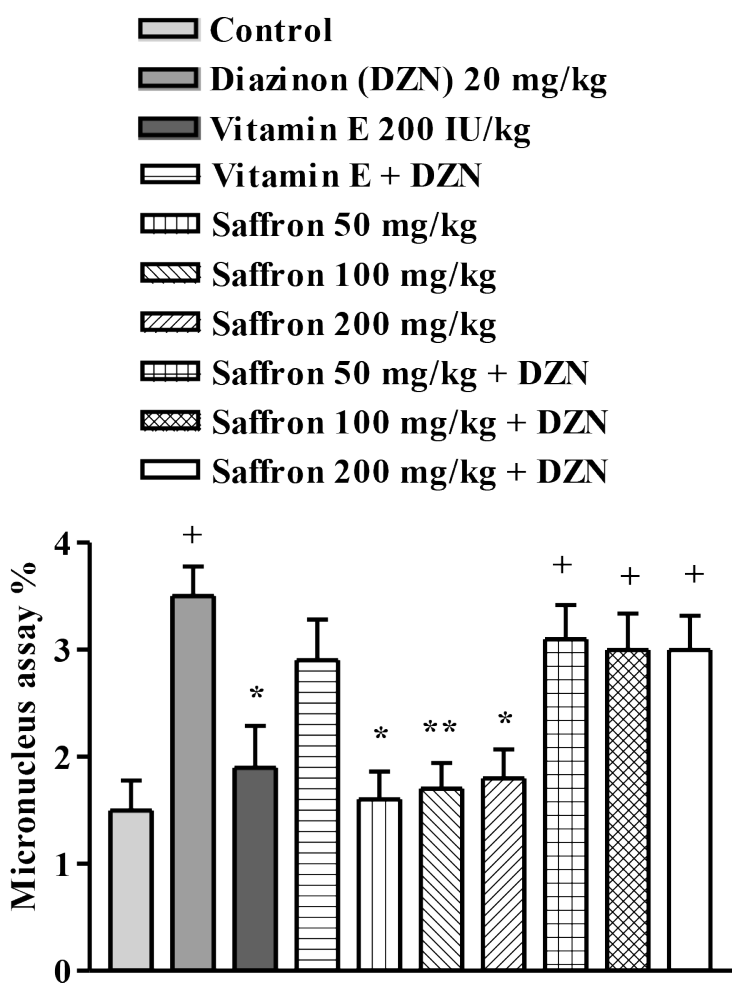

Figure 1. The effects of diazinon, aqueous extract of saffron and vitamin $\mathrm{E}$ (for 4 weeks) on blood micronucleus assay of rats. The extract, vitamin $\mathrm{E}$ and control were administered intraperitoneally three times per week. DZN in sweet almond oil was given through gavage to rats once a day. Data showed as mean \pm SEM, * Comparison with control, + Comparison with diazinon treated group. + or ${ }^{*} \mathrm{P}<0.05,++$ or ${ }^{* *} \mathrm{P}<0.01$, Tukey Kramer test, $\mathrm{n}=6$. 
Table 1. The effects of diazinon, saffron treatment (for 4 weeks) on body weight before and after of treatment $(n=6)$

\begin{tabular}{|l|l|l|}
\hline Group & Weight before treatment $(\mathrm{g})$ & Weight after 4 weeks treatment $(\mathrm{g})$ \\
\hline Control & $231.2 \pm 3.0$ & $239.3 \pm 4.5$ \\
\hline Diazinon & $230.8 \pm 3.0$ & $205.5 \pm 3.0 *$ \\
\hline Vit E & $226.0 \pm 6.8$ & $242.6 \pm 4.8$ \\
\hline Diazinon+vitE & $231.0 \pm 5.8$ & $205.8 \pm 5.7 *$ \\
\hline saffron $50 \mathrm{mg} / \mathrm{kg}$ & $230.8 \pm 3.0$ & $244.3 \pm 3.6 *$ \\
\hline saffron $100 \mathrm{mg} / \mathrm{kg}$ & $239.2 \pm 5.5$ & $244.2 \pm 2.6$ \\
\hline saffron $200 \mathrm{mg} / \mathrm{kg}$ & $231.5 \pm 2.9$ & $235.2 \pm 2.1$ \\
\hline Diazinon+saffron $50 \mathrm{mg} / \mathrm{kg}$ & $227.3 \pm 3.5$ & $204.2 \pm 5.7 * *$ \\
\hline Diazinon+saffron $100 \mathrm{mg} / \mathrm{kg}$ & $236.5 \pm 6.8$ & $214.5 \pm 7.0 *$ \\
\hline Diazinon saffron $200 \mathrm{mg} / \mathrm{kg}$ & $230.0 \pm 3.7$ & $209.7 \pm 5.6 * *$ \\
\hline
\end{tabular}

Data showed as mean $\pm \mathrm{SEM},{ }^{*}$ Comparison with control, ${ }^{*} \mathrm{P}<0.05$ or ${ }^{* *} \mathrm{P}<0.01$, Tukey Kramer test, $\mathrm{n}=6$.

Table 2. The effects of diazinon, saffron treatment (for 4 weeks) on enzymes levels.

\begin{tabular}{|c|c|c|c|c|c|c|c|c|c|}
\hline Parameter & G.G.T IU/L & Lipase IU/L & Amylase IU/L & CPK-MB IU/L & CPK IU/L & LDH IU/L & ALP IU/L & SGPT IU/L & SGOT IU/L \\
\hline Control & $25.7 \pm 5.8$ & $58.2 \pm 4.6$ & $651.5 \pm 43.2$ & $112.2 \pm 6.8$ & $535.0 \pm 5.1$ & $773.3 \pm 52.4$ & $260.0 \pm 65.7$ & $77.5 \pm 7.8$ & $176.6 \pm 13.7$ \\
\hline $\begin{array}{l}\text { Diazinon(DZ } \\
\text { N) } 20 \mathrm{mg} / \mathrm{kg} \\
\end{array}$ & $\begin{array}{l}++48.8 \pm \\
4.9\end{array}$ & $52.5 \pm 9.9$ & $674.3 \pm 40.5$ & $++197.2 \pm 8.7$ & $++1056.2 \pm 4.5$ & $\begin{array}{l}++1793.3= \\
236.0\end{array}$ & $++712 \pm 78.6$ & $+197.7 \pm 32.7$ & $+381.5 \pm 29.8$ \\
\hline $\begin{array}{ll}\begin{array}{l}\text { Vitamin } \\
200 \Pi U / k g\end{array} & E \\
\end{array}$ & $* 27.3 \pm 5.4$ & $54.0 \pm 5.4$ & $678.8 \pm 33.4$ & $* * 113.8 \pm 13.1$ & $\begin{array}{l}* * * 591.7 \pm \\
69.8\end{array}$ & $\begin{array}{l}* * * 808.3 \pm \\
94.9\end{array}$ & $* 354.8 \pm 59.4$ & $* 78.8 \pm 4.5$ & $* 190.5 \pm 16.7$ \\
\hline $\begin{array}{ll}\mathrm{DZN} & + \\
\text { Vitamin E }^{+}\end{array}$ & $35.8 \pm 3.3$ & $43.9 \pm 5.2$ & $690.0 \pm 17.5$ & $* 120.8 \pm 11.9$ & $\begin{array}{l}* * 510.7 \pm \\
60.5\end{array}$ & $\begin{array}{l}* * * 784.2 \pm \\
37.1\end{array}$ & $420.3 \pm 62.8$ & $85.2 \pm 3.6$ & $233.2 \pm 28.2$ \\
\hline $\begin{array}{ll}\text { Saffron } & 50 \\
\mathrm{mg} / \mathrm{kg} & \\
\end{array}$ & * $28.3 \pm 2.9$ & $50.4 \pm 5.0$ & $720.0 \pm 69.2$ & $* * 105.7 \pm 7.9$ & $\begin{array}{l}* * * 586.7 \pm \\
69.4\end{array}$ & $\begin{array}{l}* * * 850.0 \pm \\
63.1\end{array}$ & $418.3 \pm 46.2$ & $80.3 \pm 6.9$ & $228.3 \pm 22.3$ \\
\hline $\begin{array}{ll}\text { Saffron } 100 \\
\mathrm{mg} / \mathrm{kg}\end{array}$ & $31.5 \pm 3.1$ & $55.0 \pm 7.9$ & $663.3 \pm 72.2$ & $* * * 94.2 \pm 5.5$ & $\begin{array}{l}* * * 560.0 \pm \\
65.4\end{array}$ & $\begin{array}{l}* * * 955.0 \pm \\
92.9\end{array}$ & $488.3 \pm 88.4$ & $172.5 \pm 21.0$ & $291.7 \pm 50.6$ \\
\hline $\begin{array}{l}\text { Saffron } 200 \\
\mathrm{mg} / \mathrm{kg}\end{array}$ & $34.8 \pm 2.9$ & $48.7 \pm 4.7$ & $786.7 \pm 77.5$ & $* * 106.5 \pm 10.4$ & $\begin{array}{l}* * * 530.0 \pm \\
65.1\end{array}$ & $\begin{array}{l}* * * 806.7 \pm \\
77.9\end{array}$ & $511.7 \pm 83.2$ & $\begin{array}{l}++218.3 \pm \\
35.2\end{array}$ & $346.7 \pm 40.1$ \\
\hline $\begin{array}{lr}\text { DZN } & + \\
\text { Saffron } & 50 \\
\mathrm{mg} / \mathrm{kg} & \end{array}$ & $* 28.7 \pm 3.5$ & $58.8 \pm 4.9$ & $820.0 \pm 81.9$ & $152.5 \pm 20.3$ & $776.7 \pm 61.2$ & $+1301 \pm 95.3$ & $531.6 \pm 68$ & $176.7 \pm 17.3$ & $363.3 \pm 43.9$ \\
\hline $\begin{array}{l}\text { DZN+ } \\
\text { Saffron } 100 \\
\mathrm{mg} / \mathrm{kg}\end{array}$ & $42.0 \pm 3.1$ & $48.3 \pm 5.4$ & $643.3 \pm 65.1$ & $* * 112.8 \pm 14.1$ & $* * 605.8 \pm 74.8$ & $* * * 963.4 \pm 69.5$ & $433.3 \pm 94.0$ & $190.0 \pm 33.6$ & $+383.3 \pm 43.9$ \\
\hline $\begin{array}{l}\text { DZN+ } \\
\text { Saffron } 200 \\
\mathrm{mg} / \mathrm{kg}\end{array}$ & $+44.8 \pm 3.5$ & $54.5 \pm 5.4$ & $691.7 \pm 43.2$ & $\frac{\hbar *}{\hbar k} 102.0 \pm 7.3$ & $* * * 546.7 \pm 56.0$ & $* * * 970.0 \pm 94.1$ & $525.0 \pm 99.1$ & $++239.2 \pm 52.3$ & $++375.0 \pm 63.4$ \\
\hline
\end{tabular}

Data showed as mean $\pm \mathrm{SEM},+$ Comparison with control, ${ }^{*}$ Comparison with diazinon treated group. + or ${ }^{*} \mathrm{P}<0.05,++$ or ${ }^{* *} \mathrm{P}<0.01,+++$ or ${ }^{* * *} \mathrm{P}<0.001$, Tukey Kramer test, $\mathrm{n}=6$.

Table 3. The effects of diazinon, saffron treatment (for 4 weeks) on biochemical indices.

\begin{tabular}{|c|c|c|c|c|c|c|c|c|c|}
\hline Parameter & $\begin{array}{c}\text { Total bilirubin } \\
\mathrm{mg} / \mathrm{dl}\end{array}$ & $\begin{array}{c}\text { direct } \\
\text { bilirubin } \\
\mathrm{mg} / \mathrm{dl}\end{array}$ & $\mathrm{ALb} g / \mathrm{dl}$ & Protein $\mathrm{g} / \mathrm{dl}$ & $\mathrm{TG} \mathrm{mg} / \mathrm{dl}$ & $\begin{array}{c}\text { Cholestrol } \\
\mathrm{mg} / \mathrm{dl}\end{array}$ & $\begin{array}{c}\text { uric acid } \\
\mathrm{mg} / \mathrm{dl}\end{array}$ & $\begin{array}{c}\text { creatinine } \\
\mathrm{mg} / \mathrm{dl}\end{array}$ & Urea $\mathrm{mg} / \mathrm{dl}$ \\
\hline Control & $0.6 \pm 0.06$ & $0.4 \pm 0.06$ & $4.3 \pm 0.19$ & $7.5 \pm 0.34$ & $71.6 \pm 5.1$ & $72.7 \pm 6.9$ & $2.5 \pm 0.26$ & $1.15 \pm 0.09$ & $51.0 \pm 3.0$ \\
\hline $\begin{array}{l}\text { Diazinon(DZN) } \\
20 \mathrm{mg} / \mathrm{kg}\end{array}$ & $0.8 \pm 0.09$ & $0.3 \pm 0.04$ & $3.8 \pm 0.28$ & $+5.8 \pm 0.38$ & $74.0 \pm 7.4$ & $75.5 \pm 7.2$ & $+5.3 \pm 0.36$ & $1.23 \pm 0.11$ & $54.3 \pm 3.4$ \\
\hline $\begin{array}{lll}\text { Vitamin } & \text { E } & 200 \\
\text { IU } / \mathrm{kg} & & \end{array}$ & $0.5 \pm 0.03$ & $0.3 \pm 0.05$ & $4.1 \pm 0.28$ & $6.3 \pm 0.33$ & $79.8 \pm 4.3$ & $74.0 \pm 7.6$ & $* 3.1 \pm 0.16$ & $1.16 \pm 0.14$ & $53.3 \pm 3.8$ \\
\hline DZN + Vitamin E & $0.6 \pm 0.08$ & $0.3 \pm 0.05$ & $3.5 \pm 0.25$ & $6.1 \pm 0.45$ & $87.0 \pm 8.4$ & $72.3 \pm 5.3$ & $5.0 \pm 0.70$ & $1.28 \pm 0.12$ & $48.6 \pm 3.3$ \\
\hline $\begin{array}{ll}\text { Saffron } & 50 \\
\mathrm{mg} / / \mathrm{kg} & \end{array}$ & $0.5 \pm 0.05$ & $0.3 \pm 0.04$ & $4.3 \pm 0.14$ & $* * 7.8 \pm 0.36$ & $69.2 \pm 8.2$ & $72.8 \pm 5.7$ & $3.8 \pm 0.19$ & $1.20 \pm 0.13$ & $57.2 \pm 5.0$ \\
\hline Saffron 100 & $0.5 \pm 0.06$ & $0.2 \pm 0.04$ & $4.2 \pm 0.19$ & $* 7.6 \pm 0.25$ & $70.8 \pm 5.1$ & $73.6 \pm 4.9$ & $+++6.2 \pm 0.28$ & $1.20 \pm 0.13$ & $54.3 \pm 4.5$ \\
\hline $\begin{array}{ll}\text { Saffron } & 200 \\
\mathrm{mg} / \mathrm{kg} & \end{array}$ & $0.5 \pm 0.07$ & $0.2 \pm 0.06$ & $4.1 \pm 0.18$ & $* * * 7.9 \pm 0.34$ & $74.0 \pm 5.5$ & $72.5 \pm 5.5$ & $+++6.0 \pm 0.32$ & $1.4 \pm 0.10$ & $54.7 \pm 4.1$ \\
\hline $\begin{array}{l}\text { DZN + Saffron } \\
50 \mathrm{mg} / \mathrm{kg}\end{array}$ & $0.6 \pm 0.04$ & $0.3 \pm 0.05$ & $4.2 \pm 0.30$ & $+++5.2 \pm 0.27$ & $68.7 \pm 2.7$ & $74.3 \pm 4.9$ & $* * * 2.7 \pm 0.25$ & $1.20 \pm 0.12$ & $54.1 \pm 4.6$ \\
\hline $\begin{array}{l}\text { DZN+ Saffron } \\
100 \mathrm{mg} / \mathrm{kg}\end{array}$ & $0.5 \pm 0.07$ & $0.3 \pm 0.03$ & $4.1 \pm 0.19$ & $7.0 \pm 0.35$ & $73.5 \pm 5.5$ & $76.0 \pm 4.0$ & $+++5.7 \pm 0.30$ & $1.20 \pm 0.09$ & $55.0 \pm 5.0$ \\
\hline $\begin{array}{l}\text { DZN+ Saffron } \\
200 \mathrm{mg} / \mathrm{kg}\end{array}$ & $0.6 \pm 0.06$ & $0.2 \pm 0.05$ & $3.9 \pm 0.14$ & $6.9 \pm 0.31$ & $78.8 \pm 6.7$ & $74.8 \pm 4.6$ & $+++5.8 \pm 0.36$ & $1.30 \pm 0.12$ & $53.0 \pm 4.4$ \\
\hline
\end{tabular}

Data showed as mean \pm SEM,+ Comparison with control, ${ }^{*}$ Comparison with diazinon treated group. + or ${ }^{*} \mathrm{P}<0.05,++$ or ${ }^{* *} \mathrm{P}<0.01,+++$ or ${ }^{* * *} \mathrm{P}<0.001$, Tukey Kramer test, $\mathrm{n}=6$. 
Table 4. The effects of diazinon, saffron treatment (for 4 weeks) on hematological indices

\begin{tabular}{|c|c|c|c|c|c|c|c|}
\hline Parameter & $\begin{array}{l}\text { RBC ChE } \\
\text { activity } \\
\text { U/ml/pack cell }\end{array}$ & $\begin{array}{l}\text { Rethiculocyte } \\
(\%)\end{array}$ & $\begin{array}{l}\text { Thrombocytes (103 } \\
\text { mm-3) }\end{array}$ & Hematocrit (\%) & Hemoglobin(g/dl) & $\begin{array}{l}\mathrm{RBC} \\
\mathrm{m}-3)\end{array}$ & $\begin{array}{l}\text { WBC } \quad(103 \\
m m-3)\end{array}$ \\
\hline Control & $1.58 \pm 0.15$ & $2.6 \pm 0.32$ & $921.2=71.5$ & $49.7 \pm 1.3$ & $15.5 \pm 0.4$ & $7.3 \pm 0.4$ & $8.5 \pm 0.5$ \\
\hline Vitamin E $200 \mathrm{IU} / \mathrm{kg}$ & $* 1.48 \pm 0.17$ & $* * * 3.1 \pm 0.27$ & $* 897.7 \pm 64.3$ & $* 48.4 \pm 1.4$ & $* 15.2 \pm 0.4$ & $* 7.4 \pm 0.4$ & $8.8 \pm 1.3$ \\
\hline DZN + Vitamin E & $0.98 \pm 0.16$ & $* * 4.0 \pm 0.55$ & $706.8 \pm 70.4$ & $* 48.4 \pm 1.9$ & *1 $5.2 \pm 0.4$ & $* * 7.9 \pm 0.5$ & $8.1 \pm 1.0$ \\
\hline Saffron $50 \mathrm{mg} / \mathrm{dl} \mathrm{mg} / \mathrm{kg}$ & ** $1.81 \pm 0.24$ & $* * * 3.3 \pm 0.41$ & $* 884.2 \pm 64.5$ & $47.9 \pm 1.3$ & $14.8 \pm 0.5$ & $7.2 \pm 0.5$ & $6.5 \pm 1.1$ \\
\hline Saffron 100 & $* * * 2.0 \pm 0.24$ & $* * 3.6 \pm 0.39$ & $* 889.9 \pm 80.7$ & $* 48.5 \pm 1.3$ & $* 15.3 \pm 0.4$ & $* 7.5 \pm 0.4$ & $8.2 \pm 1.0$ \\
\hline Saffron $200 \mathrm{mg} / \mathrm{dl}$ & $* * * 2.18 \pm 0.29$ & $* * 2.7 \pm 0.37$ & $* 925.3 \pm 65.9$ & $* 48.6 \pm 1.1$ & $* 15.5 \pm 0.3$ & $* 7.5 \pm 0.6$ & $* *+13.7 \pm 0.5$ \\
\hline DZN + Saffron $50 \mathrm{mg} / \mathrm{kg}$ & $+0.65 \pm 0.13$ & $+5.4 \pm 0.51$ & $624.3 \pm 61.9$ & $41.3 \pm 1.7$ & $13.3 \pm 0.6$ & $6.9 \pm 0.3$ & $8.2 \pm 0.8$ \\
\hline DZN + Saffron $100 \mathrm{mg} / \mathrm{kg}$ & $0.76 \pm 0.14$ & $++6.8 \pm 0.5$ & $746.3 \pm 60.1$ & $* 48.3 \pm 1.5$ & $* 15.2 \pm 0.7$ & $6.6 \pm 0.4$ & $8.8 \pm 1.2$ \\
\hline DZN+ Saffron $200 \mathrm{mg} / \mathrm{kg}$ & $0.81 \pm 0.09$ & $* * 4.1 \pm 0.7$ & $* 890.8 \pm 64.5$ & $* 49.3 \pm 1.3$ & $* 15.4 \pm 0.6$ & $* 7.6 \pm 0.3$ & $* *+13.7 \pm 0.8$ \\
\hline
\end{tabular}

Data showed as mean $\pm \mathrm{SEM},+$ Comparison with control, ${ }^{*}$ Comparison with diazinon treated group. + or ${ }^{*} \mathrm{P}<0.05,++$ or ${ }^{* *} \mathrm{P}<0.01,+++$ or ${ }^{* * *} \mathrm{P}<0.001$, Tukey Kramer test, $\mathrm{n}=6$. 


\section{References}

1. Bosak A. Organophosphorus compounds: classification and enzyme reactions. Arh Hig Rada Toksikol. 2006; 57: 445-57.

2. Jokanović M,Kosanović M. Neurotoxic effects in patients poisoned with organophosphorus pesticides. Environ Toxicol Pharmacol. 2010; 29: 195-201.

3. Kovacic P. Mechanism of organophosphates (nerve gases and pesticides) and antidotes: electron transfer and oxidative stress. Curr Med Chem. 2003; 10: 2705-9.

4. Shadnia S, Azizi E, Hosseini R, Khoei S, Fouladdel S, Pajoumand A, et al. Evaluation of oxidative stress and genotoxicity in Organophosphorus insecticide formulators. Hum Exp Toxicol. 2005; 24(9): 439-45.

5. Shah M,Iqbal M. Diazinon-induced oxidative stress and renal dysfunction in rats. Food Chem Toxicol. 2010; 48(12): 3345-53.

6. Rezaee R,Hosseinzadeh H. Safranal: From an aromatic natural product to a rewarding pharmacological agent. Iran J Basic Med Sci. 2013; 16(1): 12-26.

7. Schmidt M, Betti G,Hensel A. Saffron in phytotherapy: pharmacology and clinical uses. Wien Med Wochenschr. 2007; 157(13-14): 315-9.

8. Alavizadeh S,Hosseinzadeh H. Bioactivity assessment and toxicity of crocin: a comprehensive review. Food Chem Toxicol. 2014; 64: 65-80.

9. Hosseinzadeh H,Nassiri-Asl M. Avicenna's (Ibn Sina) the Canon of Medicine and saffron (Crocus sativus): a review. Phytother Res. 2013; 27(4): 475-83.

10. Rastgoo M, Hosseinzadeh $\mathrm{H}$, Alavizadeh H, Abbasi A, Ayati Z,Jaafari MR. Antitumor activity of PEGylated nanoliposomes containing crocin in mice bearing C26 colon carcinoma. Planta Med. 2013; 79(6): 447-51.

11. Vahdati Hassani F, Naseri V, Razavi B, Mehri S, Abnous $\mathrm{K}$, Hosseinzadeh $\mathrm{H}$. Antidepressant effects of crocin and its effects on transcript and protein levels of CREB, BDNF, and VGF in rat hippocampus. DARU J Pharmac Sci. 2014; 22(1): 16.

12. Amin B, Malekzadeh M, Heidari M,Hosseinzadeh H. Effect of Crocus sativus extracts and its active constituent safranal on the harmaline-induced tremor in mice. Iran J Basic Med Sci. 2015; 18(5): 449-58.

13. Hosseinzadeh H,Talebzadeh F. Anticonvulsant evaluation of safranal and crocin from Crocus sativus in mice. Fitoterapia. 2005; 76(7-8): 722-4.

14. Hosseinzadeh H, Sadeghnia HR,Rahimi A. Effect of safranal on extracellular hippocampal levels of glutamate and aspartate during kainic acid treatment in anesthetized rats. Planta Med. 2008; 74(12): 1441-5.

15. Sadeghnia HR, Cortez MA, Liu D, Hosseinzadeh H,Carter Snead O. Antiabsence effects of safranal in acute experimental seizure models: EEG and autoradiography. J Pharm Pharm Sci. 2008; 11(3): 1-14.

16. Hosseinzadeh $\mathrm{H}$,Khosravan V. Anticonvulsant effects of aqueous and ethanolic extracts of Crocus sativus L. stigmas in mice. Arch Iran Med. 2002; 5(1): 44-7.

17. Razavi B,Hosseinzadeh H. Saffron as an antidote or a protective agent against natural or chemical toxicities.
DARU J Pharmac Sci. 2015; 1; 23: 31.

18. Hosseinzadeh H, Modaghegh M, Saffari Z. Crocus sativus L. (saffron) extract and its active constituents (crocin and safranal) on ischemia-reperfusion in rat skeletal muscle. Evid Based Complement Alternat Med. 2009; 6(3): 343-50.

19. Hosseinzadeh H, Sadeghnia H, Ziaee T,Danaee A. Protective effect of aqueous saffron extract (Crocus sativus L.) and crocin, its active constituent, on renal ischemia-reperfusion-induced oxidative damage in rats. J Pharm Pharmac Sci. 2005; 8(3): 387-93.

20. Mehdizadeh R, Parizadeh M, Khooei A, Mehri S,Hosseinzadeh H. Cardioprotective Effect of saffron extract and safranal in isoproterenol-induced myocardial infarction in Wistar rats. Iran J Basic Med Sci. 2013; 16(1): 56-63.

21. Hosseinzadeh H,Sadeghnia H. Safranal, a constituent of Crocus sativus (saffron), attenuated cerebral ischemia induced oxidative damage in rat hippocampus. J Pharm Pharmac Sci. 2005; 8(3): 394-9.

22. Kanakis C, Tarantilis P, Pappas C, Bariyanga J, Tajmir-Riahi H,MG. P. An overview of structural features of DNA and RNA complexes with saffron compounds: Models and antioxidant activity. J Photochem Photobiol B. 2009; 95(3): 204-12.

23. Hayashi M, Sofuni T,Ishidate JM. An application of acridine orange fluorescent staining to the micronuclear test. Mut Res. 1983; 120: 241-7.

24. Ellman G, Courtney K, Andres JV,Featherstone R. A new and rapid colorimetric determination of acetylcholinesterase activity. Biochem Pharmacol. 1961; 7(2): 88-95.

25. Jokanovi囚 M,Kosanovi囚 M. Neurotoxic effects in patients poisoned with organophosphorus pesticides. Environ Toxicol Pharmacol. 2010; 29(3): 195-201.

26. Damodar D, D'Souza UJ,Bhat S. Protective role of Vitamin E: On diazinon-induced hepatotoxicity by biochemical and histological alterations in wistar rats. Nat J Physiol Pharm Pharmacol. 2015; 5: 398-406.

27. Beydilli H, Yilmaz N, Cetin ES, Topal Y, Celik OI, Sahin C, et al. Evaluation of the protective effect of silibinin against diazinon induced hepatotoxicity and free-radical damage in rat liver. Iran Red Crescent Med J. 2015; 17(4): e25310.

28. Hariri A, Moallem S, Mahmoudi M, Memar B,Hosseinzadeh H. Sub-acute effects of diazinon on biochemical indices and specific biomarkers in rats: protective effects of crocin and safranal. Food Chem Toxicol. 2010; 48(10): 2803-8.

29. Razavi B, Hosseinzadeh H, Movassaghi A, Imenshahidi M,Abnous K. Protective effect of crocin on diazinon induced cardiotoxicity in rats in subchronic exposure. Chem-Biol Interact. 2013; 20(3)3: 547-55.

30. Waly M, El-Mezayen HA,Mohyee M. Potential role of curcumin and garlic acid against diazinon and propoxur hepatotoxicity. Int J Pharm Sci Rev Res. 2015; 33(2): 50-7.

31. Abdel-Daim MM, Taha R, Ghazy EW,El-Sayed YS. Synergistic ameliorative effects of sesame oil and alpha-lipoic acid against subacute diazinon toxicity in rats: Hematological, biochemical, and antioxidant 
studies. Can J Physiol Pharmacol. 2015; 94(1): 81-8.

32. Lari P, Abnous K, Imenshahidi M, Rashedinia M, Razavi M,Hosseinzadeh $\mathrm{H}$. Evaluation of diazinon- induced hepatotoxicity and protective effects of crocin. Toxicol Ind Health. 2015; 31(4): 367-76.

33. Chen Y, Zhang H, Tian X, Zhao C, Cai L, Liu Y, et al. Antioxidant potential of crocins and ethanol extracts of Gardenia jasminoides ELLIS and Crocus sativus L.: a relationship investigation between antioxidant activity and crocin contents. Food Chem Toxicol. 2008; 109(3): 484-92.

34. Moallem S, Hariri A, Mahmoudi M,Hosseinzadeh H. Effect of aqueous extract of Crocus sativus L. (saffron) stigma against subacute effect of diazinon on specific biomarkers in rats. Toxicol Ind Health. 2014; 30(2): 141-6. .

35. Razavi B, Hosseinzadeh H, Abnous K,Imenshahidi M. Protective effect of crocin on diazinon induced vascular toxicity in subchronic exposure in rat aorta ex-vivo. Drug Chem Toxicol. 2014; 37(4): 378-83.

36. Goyal SN, Arora S, Sharma AK, Joshi S, Ray R, Bhatia J, et al. Preventive effect of crocin of Crocus sativus on hemodynamic, biochemical, histopathological and ultrastuctural alterations in isoproterenol induced cardiotoxicity in rats. Phytomedicine. 2010; 17(3-4): 227-32.

37. Puri A, Maulik SK, Ray R,Bhatnagar V. Electrocardiographic and biochemical evidence for the cardioprotective effect of vitamin $\mathrm{E}$ in doxorubicin-induced acute cardiotoxicity in rats. Eur J Pediatr Surg. 2005; 15(6): 387-91.

38. El-Shenawy NS, Al-Eisa RA, El-Salmy F,Salah O. Prophylactic effect of vitamin E against hepatotoxicity, nephrotoxicity, haematological indices and histopathology induced by diazinon insecticide in mice. Curr Zool. 2009; 55(3): 219-26.

39. Yehia MAH, El-Banna SG,Okab AB. Diazinon toxicity affects histophysiological and biochemical parameters in rabbits. Exp Toxicol Pathol. 2007; 59(3-4): 215-25.

40. Kehrer JP, LG L. Pyridine nucleotides and the reduction of GSSG in hypoxic heart tissue exposed to diamide. Free Rad Biol Med. 1993; 15: 520.

41. Campbell K. Laboratory diagnosis and investigation of anaemia. Nurs Times. 2005; 101(22): 36-9.

42. Hariri AT, Moallem SA, M M,H. H. The effect of crocin and safranal, constituents of saffron, against subacute effect of diazinon on hematological and genotoxicity indices in rats. Phytomedicine. 2011; 18(6): 499- 504.

43. Shadnia S, Azizi E, Hosseini R, Khoei S, Fouladdel S, Pajoumand A, et al. Evaluation of oxidative stress and genotoxicity in organophosphorus insecticide formulators. Hum ExpToxicol. 2005; 24(9): 439-45.

44. Hosseinzadeh H, Abootorabi A,HR. S. Protective effect of Crocus sativus stigma extract and crocin (trans-crocin 4) on methyl methanesulfonate-induced DNA damage in mice organs. DNA Cell Biol. 2008; 27(12): 657-64.

45. Hosseinzadeh $\mathrm{H}$,Sadeghnia H. Effect of safranal, a constituent of Crocus sativus (saffron), on methyl methanesulfonate (MMS)-induced DNA damage in mouse organs: an alkaline single-cell gel electrophoresis (comet) assay. DNA Cell biol. 2007; 26(12): 841-6.

46. Premkumar K, Abraham S, Santhiya S, Gopinath P,Ramesh A. Inhibition of genotoxicity by saffron (Crocus sativus L.) in mice. Drug Chem Toxicol. 2001; 24(4): 421-8. 